\title{
동티모르 원조공여국 회의 결과
}

개발원조위원회 정기회의(Timor-Leste and Development Partner's Meeting)가 동티모르 정 부와 World Bank 공동주최로 4. 25(월) 26(화)간 개최된 바, 주요 내용은 다음과 같음.

\section{I. 핵심요지}

묘제회의에서 지난 1 년간 동안의 국가발전계획 (NDP) 이행상황에 대해 평가하고 2005/6 회계연 도 예산안과 향후 재정운용 방향에 대해 논의하 였음. 또한 donor(국가/국제기구)들의 지원공여 현황 발표와 향후 지원방향과 계획에 대한 입장 표명이 있었음.

ㅁ 공여국들은 동티모르가 지난 1 년간 제반분야에서 현저히 가시적인 성과를 이룩하였다고 평가하고 재정운용 관련 국제유가 급등에 따른 티모르해 석유-가스 개발수익의 현저한 증가(FYO4 41백
만 불 $\mathrm{FY05} \mathrm{243백만불),} \mathrm{재정긴축노력} \mathrm{및} \mathrm{과세}$ 강화노력에 힘입어 건실한 재정이 유지되고 있음 을 환영하고 미래 후손을 위한 석유기금 적립을 높이 평가함.

ㅁ향후 주재국은 정치적 불안정 요소가 있으나 경 제적으로는 건조한 성장세를 유지할 것으로 전망 되며 2005년 4월 내 - 외국인 투자법 제정으로 경 제가 보다 활성화될 것으로 전망됨.

ㅁ동티모르대사관은 그간 우리 기업의 ⿶ㅝㅇ주재국 투 자에 대해 보수적 입장을 견지하여 왔으나 중 장기적 발전가능성을 고려 '긍정적 고려' 입장으 로 상향 조정함.

\section{II. 상세사항}

1) 회의 참가국

ㅁ국가:호주, 브라질, 캐나다, 중국, EU, 프랑스, 
핀란드, 독일, 인도네시아, 아일랜드, 한국, 쿠웨 이트, 말레이시아, 뉴질랜드, 노르웨이, 필리핀, 일본, 포르투갈, 스웨덴, 태국, 영국, 미국 (22개국) 묵제기구:UNMISET, UNDP, UNICEF, WHO, UNIFEM, UNFPA, UNESCO, UNHABITAT, UNIDO, UNOPS, FAO, ILO, IOM, ADB, $\mathrm{IMF}(15$ 개 국제기구)

ㅁ민간부문, 시민사회단체 대표

\section{2) 기조발언}

$\square$ Alkatiri 총리/Francisco Guterres 국회의장 (동일 취지)

- 독립 이후 3 년간 제반분야에서 동티모르 정부가 이룩한 성과를 열거하고 유엔 천년개발계획 $(\mathrm{MDGs})$ 에 충실한 $\mathrm{NDP}$ 를 착실하게 진전시키고 있음을 강조

-Sector Investment Programs(17개)하에 Sector Working Groups(10개)을 통하여 체계 적인 개발계획 수립과 역량 배양(capacity building)을 추진하고 있고 경제활성화를 위한 투자법 제정과 투자수출진흥청 신설 노력, 민주 주의 증진을 향한 지방기초자치단체 선거 실시 를 부각

-2006 회계연도에는 인프라구축, 공무원 교육훈 련에 중점을 두어 사회경제 발전기조를 다지고 지방분권을 촉진하는 방향으로 정부 구조조정 을 하여 민주적이고 안정된 평화국가로 발전시 키기 위해 진력하고 있음을 강조

-알카티리 총리는(이달 초 "학교 교과과정에서
카톨릭 수업을 중단하여야 한다" 는 자신의 발언 에 항의하여 4 월 18 일부터 현재까지 2주간 딜리 에서 계속되고 있는 카톨릭계의 항의시위를 염 두에 두고) 빈곤, 문맹, 의사소통 인프라구축 미 흡, 진실의 오도가 민주주의와 법치(rule of law) 구현을 왜곡시키는 장애물이라고 언급 Kassum W/B 부총재(Zhu Xian 동티모르 담당 과장 대독)

-동티모르는 독립 이후 지난 3 년 동안 천년개발 목표(MDG)를 모범적으로 반영한 $\mathrm{NDP}$ 를 잘 이 행하여 왔으며 특히 석유개발수익을 투명하고 건실하게 운용하고 석유자원이 현재의 세대뿐 만 아니라 후손들도 공유할 수 있는 기본 토대를 구축하였음을 높이 평가

- 동티모르가 지속가능한 발전을 이룰 수 있도록 공여국들이 무상지원 공여(CSP)을 지속하여 줄 것을 촉구하고 사법분야 등 핵심정부기능이 원 활히 작동되도록 전략적이고 집중적인 역량 개 발을 위한 동티모르 정부와 공여국들의 공동의 노력이 긴요함을 강조

※ CSP(Consolidation Support Program)는 이전의 TSP(Transitional Support Program)를 전환한 것으 로 공여국 무상지원공여프로그램

3) 의제별 토의결과

의제 1

재정(Fiscal Challenges and Opportunities) 
ㅁ동티모르 정부 및 W/B 발표

- 회의를 주재한 Alkatiri 총리와 Zhu Xian W/B 대표가 기조발언 발표를 통하여 개괄적으로 언 급하고 Boavida 기획재무장관과 Bassarewan 차관이 구체 내용에 대해 발표

\section{가. 2005 회계연도 예산집행}

2004 회계연도 기간 중 세입은 티모르해 개발소 득이 예상보다 많이 유입되고 세정개선으로 국세 수입(특히 관세)이 증대되어 당초 예상치인 169 백 만불보다 107 백만불 증가한 276 백만불 예상. 반 면, 재정지출은 예상보다 저조 ※2004/5회계연도 기간은 2004. 7-2005. 60|며 2005 회계연도로도 표시

\section{나. 2006 회계연도 예산안}

2005년 7월부터 개시되는 FY06 예산은 118백만 불로 빈곤층에 중점을 두어 편성, 보건 · 교육부문 에 전체예산의 $35 \%$, 교육예산 중 $45 \%$ 를 초등교 육에, 보건예산 중 $40 \%$ 를 병원지출에 배정, 경찰 과 국방에는 전체 예산의 $19 \%$ 로 편성

〈중기 예산 전망〉

(단위 : 백만US\$)

\begin{tabular}{l|r|r|r|r|r|r}
\hline & FY05 & FY06 & FY07 & FY08 & FY09 & FY06-09 \\
\hline 세입 & 306.5 & 205.6 & 234.9 & 232.5 & 262.7 & 935.7 \\
국세 & 33.2 & 36.4 & 38.6 & 40.8 & 43.7 & 159.5 \\
티모르해 개발수익 & 242.6 & 158.7 & 185.7 & 181.2 & 218.5 & 744.1 \\
공여국무상원조(CSP) & 30.7 & 10.5 & 10.5 & 10.5 & 0.5 & \\
세출 & 78.7 & 119.6 & 106.1 & 112.0 & 109.6 & 436.7 \\
재정흑자 & 227.8 & 86.0 & 128.8 & 120.5 & 153.1 & 488.4 \\
Financing Gap & 0 & 0 & 0 & 0 & 0 & 0 \\
\hline
\end{tabular}

※ 재정흑자는 대부분 석유기금으로 적립

\section{다. 경제지표}

맙유운단 유전은 2004년 4월 이래 본격적으로 가 동중이며 향후 새로운 유전개발 가능성 상당 -석유생산으로 인해 GNI는 현저히 증가하였으 며 비석유부문 GDP도 미약하나마 증가세를 보 여 2002 2003년 2년간 마이너스 성장에서 벗 어나 2004 년도에는 $2 \%$ 성장 시현

- 인구증가율(연 $3 \%$ 수준)이 높아 실업률은 오히 려 증가하였으며 특히 비숙련노동력은 아직도 현저히 높은 상태로 빈곤감축을 위해서는 농촌 지역의 노동생산성 제고가 시급한 실정 - 물가상승률은 연 2.5\% 수준으로 안정적 -2004년도 비석유부문 수출은 8백만불이며 이중 커피수출이 약 700 만불로 전체 수출의 대부분 차지(커피수출은 국제가격 상승과 시장개척에 힘입어 크게 증가)

-금융부문 활동은 2004년 중 빠르게 확대되어 예금잔액은 2003년도 72백만불에서 2004년도 에 84백만불로 증가하였으며 대출잔액도 전년 대비 수 배 증가

-2004년 중 외국인투자는 많지 않았음. 투자활 성화를 위한 법제는 많은 진전을 이룩하였으나 회사등록절차는 복잡하고 불분명함. 투자수출 진흥청이 2005년 중반에 설립되어 One-stop 서비스를 제공할 예정

-노동부문에서는 2005년 중 한국으로 동티모르 노동인력 송출이 예정되어 있으며 말레이시아 로의 송출도 추진되고 있음.

- 전 분야를 망라하여 17 개 부문의 부문별 투자계 
획(SIPs : Sector Investment Programs)이 수 립 - 이행중

\section{ㅁ공여국측 발언 요지}

- 공여국들은 동티모르 재정건전성 확보와 석유 기금 확충 노력을 평가하고 향후 직면한 실업문 제 해소, 저소득층 계층 지원확대 차원에서 도 로, 통신 등 인프라 확대를 위한 재정지출 필요 성을 제기. 이외 별다른 토의 없이 조기 종결됨.

\section{의제 2}

\section{Capacity Building}

ㅁ 동티모르 정부 및 $\mathrm{W} / \mathrm{B}, \mathrm{UNMISET}$ 발표

-Capacity building 총괄기관인 $\mathrm{CDCU}$ (Capacity Development Coordination Unit) 의 Augusto Barreto 소장은 중기 능력배양을 위해 (1)자문관과 현장 훈련교육 (2)해외훈련 (3) 부처간 교차훈련 (4)부처 내 별도 교육훈련 실시 계획에 대해 상세 언급하고 공여국의 계속적인 지원을 요청하였음.

-UN 대표인 하세가와는 동티모르 발전에 있어서 가장 핵심적인 문제는 capacity building임을 강조하고 동티모르 정부에서 필요하다고 요청 한 자문관 400 명 중 사법, 재정, 법률분야를 중 심으로 58 개 직위를 핵심직위로 선정, 이를 안 보리에 보고 예정임을 언급하고 UN 산하기관, 국제기구, 공여국가들이 자문관 충원을 위해 공 동 노력하여 줄 것을 요청

-(공여국측이 제기한 동티모르 정부의 capacity building 노력 미흡 및 전략 부족 지적에 대해) 동티모르 정부대표로 나선 행정자치 장관은 많 은 노력과 비용을 들여 공무원들을 교육훈련시 켜 놓으면 이들이 그만 두고 보다 더 많은 보수 를 찾아 international organization으로 옮겨 가 버리거나 해외로 가버리기 때문에 capacity building상 어려움이 많다고 토로

ㅁ공여국 반응

-대부분 공여국들은 사법, 재정분야에서 capacity building과 부정부패 없는 정부 건설 이 중요하다는데 인식을 공유

- 영국과 아일랜드 대표는 그간 많은 자문관들이 와서 동티모르 공무원들을 교육훈련하기 위해 노력하였으나, 자문관들의 적극적인 관심 결여 와 공무원들의 의지 결핍으로 인해 실효성 있게 이행되지 못하고 있음을 지적하고 capacity building을 효율적으로 추진하기 위해서는 일회 성이 아닌 전략적 접근이 필요함을 강조하고 이 를 위한 제도화 구축 필요성을 강조

-또한 capacity building 총괄기관인 CDCU가 인적자원육성의 중요임무를 수행할 수 있는 조 직과 역량을 갖추지 못한 실정이기 때문에 $\mathrm{CDCU}$ 기능강화를 주문

- $\mathrm{IOM}$, 아일랜드 대표는 수도인 딜리에서는 각종 세미나나 회의를 통하여 capacity building을 이야기하지만 정작 지방에서는 capacity building에 무관심한 실정임을 지적하고 구호로 만 그치지 않고 capacity building이 지속적으 로 추진되기 위해서는 institution building과의 
병행이 중요함을 강조

\section{4) 주요국 발언요지}

\section{가. 미국}

ㅁ행정·사법제도 강화, 지방정부의 능력배양 및 지방으로의 행정서비스 확대강화, 경쟁력 있는 민간기업의 육성, 농업생산성 향상과 시장활성화 를 통한 고용확대 및 소득창출, 일반국민들의 기 초생활여건 개선 필요성을 강조하고 특히 부패척 결의 중요성에 대해 언급

미국은 향후에도 경제활성화, 민주주의 공고화, 보건 서비스 확산에 중점을 두어 지원할 것임을 천명하고 동티모르 정부도 자체 노력을 경주해 줄 것을 당부

\section{나. 일본}

Fukusihma 외무성 의회차관(참의원)은 Post UNMISET에도 평화를 지속시키기 위해서는 국 제사회의 지속적인 지원이 중요함을 강조하고 어 떤 형태로든 유엔의 존속이 필요함을 강조. 특히 자신이 헬기로 국경지역을 직접 방문하여 유엔군 (UN organized troops)의 중요성을 인식하였음 을 강조

ㅁ고이즈미 총리의 자카르타 아시아-아프리카 정 상회의 발언을 인용하여 경제발전, 평화구축, 국 제협력증진을 위한 일본 정부의 벙개도국 지원 정책에 대해 언급

ㅁ일본은 1999년 서약한 130 백만불, 2002년 서약 한 60 백만불을 충실히 이행하였음을 강조하고
2005 년에 추가로 20 백만불 지원 예정임을 밝히 고 인적자원개발과 제도구축, 인프라, 농업개발, 평화공고화, 선정 등 5 개 분야에 중점을 두어 지 원하고 있음을 언급

2004년 1월 서명된 기술협력협정이 발효되면 전 분야에서 기술협력을 제공할 것임을 언급하면서 동티모르측의 조속한 비준을 촉구

\section{다. 중국}

ㅁ 중국은 외교부청사, 대통령궁, 재향군인 주택 100 채 건축 등 3 개 건축사업을 지원키로 약속한 바, 외교부청사 건축계약을 이달중 체결하고 곧 건축 공사를 개시할 예정이며 대통령궁은 설계단계에 있으며, 재향군인 주택 건축은 동티모르 정부가 주택부지를 결정하면 전문가를 파견할 예정임.

ㅁㅜㅜㅇ국 의사 파견, 연수생 초청·훈련지원, 주중국 동티모르 대사관 설치 및 운영 일체 지원 언급 ㅁ중국과 포르투갈사용국간 경제협력포럼 하에서 양국간 경제협력과 투자촉진을 도모하고 있음. 중 국의 Yuan Longping High-Tech 농업회사는 hybrid 벼 재배를 지원하고 있고 PetroChina와 $\mathrm{BGP}$ 사는 동티모르 내륙과 해역에서 석유자원개 발 지질조사를 수행하고 있음.

\section{라. 호주}

ㅁ동티모르가 향후 공여국 지원 없이도 자력으로 지속적인 발전을 이루어 나가기 위해서는 계속해 서 건전한 재정운용이 요구됨. 허약한 정부행정 기능으로는 성장과 빈곤경감을 이룰 수 없기 때 
문에 투자촉진을 위한 법제와 제도 구축 중요성

을 역설하고 동티모르가 부정부패 없는 국가로 발전하기 위해 정부가 보다 적극적인 역할을 할 것을 주문

ㅁ 빈곤계층에 대한 기초서비스 제공 노력 강화 필 요성, 식량안보 차원에서 개량종자 도입 - 배포를 위한 농림수산부와 Australian Center for International Agricultural Research(ACIAR) 간 협력사업에 대해 언급하고 호주는 연간 4,000 만 호주달러 수준의 지원을 계속해 나갈 예정임 을 밝힘.

\section{마. 유럽연합}

ㅁ 진행 중인 지방기초단체 선거(13개 District 중 5 개 District에서 실시), 인도네시아 및 호주와 국 경선 획정 진전을 평가

ㅁ중범죄단과 진실화해위원회가 추가적 조치 없이 종결될 경우 1999년시 잔학행위를 한 자들에게 면죄부를 주거나 오도되지 않을까 우려하고 있음 을 언급하고 대립과 갈등관계에 있는 경찰과 군 간의 대화 촉구

\section{바. IMF}

ㅁ당면한 실업문제해결과 경제활성화, 빈곤축소를 위해서는 민간부문 활성화가 시급함을 강조하고 이를 위한 법적-제도적 완비를 가속화할 것을 촉구

ㅁ 경제성장과 안정이 조화될 수 있도록 경제시스템 구축 필요 주장

\section{사. 인도네시아}

믐년 4월 8 9일간 동티모르를 공식 방문한 유도 요노 대통령이 밝힌 바와 같이 인도네시아는 동 티모르의 안정과 번영이 지역안보에도 직결된다 는 공동 인식 아래 동티모르가 보다 강한 나라로 발전하도록 지원할 것임을 밝힘.

\section{5)우리나라 발언 요지}

ㅁ동티모르 정부의 국가발전계획수립과 이행에 순 조로운 진전이 있음을 평가하고 특히 법적 - 제도 적 정비, 재정운영, 국정능력배양, 투명성 제고 등 분야에서 많은 진전이 있었음을 언급 ㅁ우리의 경험에 비추어 볼 때 국가발전을 이룩하 기 위해서는 교육과 직업훈련을 통한 인적자원개 발과 농촌지역 발전이 중요함을 강조하고 우리의 새마을운동의 기본취지와 정신을 소개하였음.

ㅁ특히, 스포츠분야에서 한국의 적극적인 지원 하 에 동티모르 유소년축국팀(김신환 감독 지도)이 히로시마 개최 리베리노컵 국제대회에서 2 연패하 였음을 소개하고 신생국 동티모르도 국제대회에 서 우승할 수 있는 저력을 가지고 있는 국가임을 강조함.

ㅁ정부 차원에서 연수생초청, 기자재 공여, 전문가 파견 지속 추진 및 금년 중 동티모르 노동인력도 입과 해외봉사단 파견 계획을 밝히고 스포츠, 종 교, 문화, 의료보건, 교육, IT, 농업개발 등 분야 에서 한국 민간단체 지원 실적을 소개하고 계속 적인 지원 유도 방침에 대해 언급 -지방병원건립(평화의료재단), 여성 - 아동센터 
(경기도, 구미시), 신학교건립성금지원(대구카톨 릭교구), 슈퍼콘개발프로젝트(김순권 박사), 의 료봉사단(대구달서, 경기도 등), IT 봉사단 등

〈주요국 원조공여 현황(1999-2005.4)〉

\begin{tabular}{c|c}
\hline 국가/국제기구 & 공여액 (단위 : 백만 미불) \\
\hline 포르투갈 & 199 \\
일본 & 191 \\
호주 & 186 \\
EC & 177 \\
미국 & 100 \\
영국 & 55 \\
UNDP & 42 \\
노르웨이 & 41 \\
UNICEF & 40 \\
UN & 33 \\
독일 & 32 \\
WFP & 26 \\
World Bank & 25 \\
UNHCR & 24 \\
중국 & 24 \\
스웨덴 & 20 \\
아일랜드 & 20 \\
카나다 & 18 \\
핀란드 & 17 \\
ADB & 10 \\
UNFPA & 9 \\
WHO & 8 \\
뉴질랜드 & 7 \\
네덜란드 & 6 \\
한국 & 6 \\
FAO & 3 \\
브라질 & 3 \\
\hline
\end{tabular}

※ 우리나라는 민간단체 지원 포함

\section{III. 관찰 및 평가}

\section{1. 평가}

ㅁ 공여국들은 동티모르 독립 이후 지난 3년간의 짧 은 기간 내에 제반 분야에서 현저한 가시적인 성 과를 이룩하였음을 평가

ㅁㅊㅊ근 국제유가의 고공행진으로 인해 티모르해 석 유-가스 개발수익이 예상보다 크게 증가하여 공 여국들의 지원 여부에 관계없이 당분간 재정상
어려움이 없을 것으로 전망되며 특히 정부의 건 실한 예산집행으로 인해 예산은 있으나 충분히 집행되지 못하고 있는 상황임.

ㅁ특히, 동티모르는 신생국으로 재정상 어려움을 겪으면서도 외채를 전혀 쓰지 않은 가운데(동티 모르는 World Bank, $\mathrm{ADB}$ 등 국제금융기구에서 최혜조건으로 제공하는 제로 금리의 차관도 일절 받아들이지 않고 있음), 석유자원을 미래 후손들 과 공유하기 위해 석유기금을 적립하고 있는 등 건실한 재정을 유지하고 있음. 또한 바유운단 유 전이외에 추가적으로 Greater Sunrise 유전에서 추가적으로 개발수익이 예상(2010년부터 유입될 것으로 예상되고 있어, 향후 동티모르는 경제적 으로는 다소 낙관적일 것으로 평가

믐번 회의에서 동티모르 정부는 재정여건의 호전 에 힘입어 공여국들에게 지원을 절실히 요청하는 면은 별로 없었음. 공여국들도 동티모르 정부의 노력을 전반적으로 평가하면서 일반적으로 공여 국들이 제기하는 부정부패 등 good governance 를 위한 문제 제기가 현저히 줄어들었음.

믁이사항

-최대 공여국인 일본은 금번 회의에 차관급 인사 (참의원인 Fukusihma 일본대표는 정무직으로 외무성내 서열 3 위에 해당)가 참여하여 2005년 5 월 UNMISET 임무 종료 이후에도 어떤 형태 로든 유엔 존속의 필요성을 역설하고 별도발언 을 통하여 일본정부의 대개발지원 외교정책에 대해 언급하는 등 안보리상임이사국 진출 등을 겨냥한 면이 역력하였음. 


\section{2. 중기 경제전망(동티모르대사관 관찰)}

ㅁ독립 3 년을 맞은 주재국은 유엔 등 국제사회 역할 축소에 따라 경제활동에 있어서도 외국인의 역할 이 현저히 줄어든 반면 동티모르인의 역할이 증 대되고 있음.

ㅁ햐우 마무리단계에 있는 투자관련 법령이 정비되 면 (투자법은 2005년 4월 국회통과) 외국인 투자 가 활성화되어 석유산업 이외 분야에서도 실물경 제가 활성화될 것으로 전망함.

마라서 우리 기업의 대주재국 투자도 전향적으로 검토할 필요가 있다고 판단됨.

\section{3. 건의}

만 · 동티모르 양국간 확고한 우호협력관계 지속 을 위해서는 대동티모르 개발협력을 지속적으로 추진해 나가는 것이 긴요
면재 예정인 해외봉사단 파견을 금년 중 개시, 이 를 점차적으로 확대하여 동티모르의 capacity building을 지원 필요

향우 ‘독립기념관 건립사업' 이후 신규 프로젝트 사업 추진 필요

- 프로젝트 사업으로 추진된 독립기념관은 당지 에서는 가장 모범적인 사업으로 평가받고 있음.

※마하티리 말레이사 전 총리 방문, 유도요노 인도네 시아 대통령 방문, 독일 외무장관 방문, 동티모르인도네시아 공동위원회 개최, 호주-동티모르 석유 협상 개최 회의장으로 사용

※ 영국 대사는 5 천만불을 공여하고도 독립기념관 같 은 건물을 남기지 못하였다 하면서 부러워하고 일본 대사관측도 매번 Ceremony할 때 독립기념관을 이 용하고 있다면서 높이 평가

[자료:주동티모르 대사관] 